\title{
Migrating biliary stent with final destination at the ileocecal junction causing intestinal obstruction and obstructive biliopathy
}

\author{
Darshana D Rasalkar, Bhawan K Paunipagar, Bhawna Sonavane ${ }^{1}$ \\ Department of Diagnostic Radiology and Organ Imaging, The Chinese University of Hong Kong, Prince of Wales Hospital, Ngan \\ Shing St., Shatin, New Territories, Hong Kong, 'Department of Radiology, Super Speciality Hospital, Government Medical \\ College, Nagpur, India
}

Correspondence: Dr. Darshana D Rasalkar, Department of Diagnostic Radiology and Organ Imaging, The Chinese University of Hong Kong, Prince of Wales Hospital, Ngan Shing St., Shatin, New Territories, Hong Kong, SAR. E-mail: drdarshanar@yahoo.com

\begin{abstract}
Endoscopic plastic biliary stent insertion is a minimally invasive, well-established procedure for the management of benign biliary pathology. We report a case of a migrating stent for over two days, which finally got impacted at the ileocecal junction, leading to intestinal obstruction and obstructive biliopathy. Radiological findings depicted the exact site of the dislodged biliary stent and its related complications, both of which were successfully treated in a nonoperative stepwise manner.
\end{abstract}

Key words: Biliary stent; ileocecal junction; migration

\section{Introduction}

Complications from biliary stenting are rare. One of the late complications of long-term biliary stenting includes stent dislocation and migration, ${ }^{[1]}$ which in turn can lead to visceral obstruction, depending on the site of dislodgement. ${ }^{[1]}$

\section{Case Report}

A 91-year-old woman presented with gradually increasing abdominal pain for two days. The pain was most severe in the right upper and lower quadrants. On physical examination, she had guarding, a distended abdomen, and generalized tenderness. She was mildly pyrexic at $37.7^{\circ} \mathrm{C}$ and laboratory tests showed leukocytosis $(11,400 \mathrm{wbc} /$ $\mu \mathrm{L})$. Her liver function tests were deranged, with a serum bilirubin of $141 \mu \mathrm{mol} / \mathrm{L}$ (from 32), an alkaline phosphatase (ALP) of $141 \mathrm{IU} / \mathrm{L}$ (from 76), and an ALT (alanine aminotransferase-SGPT) of 124 IU/L (from 35); C-reactive protein (CRP) was elevated to 254.9. She had a past history of endoscopic retrograde cholangiopancreaticography

DOI: 10.4103/0971-3026.73535
(ERCP)-guided plastic stent insertion for a benign biliary stricture involving the terminal common bile duct (CBD).

An abdominal radiograph showed small bowel obstruction with a dislodged biliary stent in the right iliac fossa [Figure 1A]. A review of a previous abdominal radiograph done two days prior showed a stent in the left paraumblical region, without significant dilatation of the bowel loops [Figure 1B]. A subsequent abdomen and pelvic CT scan showed impaction of the migrated stent at the ileocecal junction, resulting in proximal intestinal obstruction. The distal small bowel loops were edematous and mild inflammatory changes were noted in the adjacent mesentery and omentum [Figure 2]. There was no pneumoperitoneum.

In addition, the gall bladder (GB) was grossly distended with mild wall thickening and mild pericholecystic fluid. A $2.0 \times 1.3 \mathrm{~cm}$-sized sludge ball was noted impacted in the terminal CBD extending up to the proximal CBD $(2.2$ $\mathrm{cm}$ in diameter), with intrahepatic biliary duct dilatation [Figure 3]. The overall features were suggestive of an obstructive biliopathy, complicated by acute cholecystitis. We made a diagnosis of intestinal obstruction and obstructive biliopathy, both complications related to 


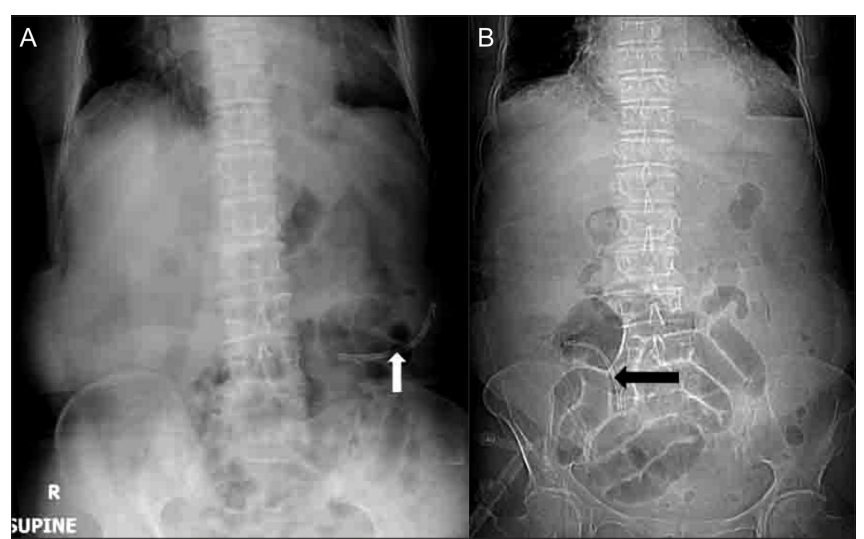

Figure $1(A, B)$ : Supine plain abdominal radiographs obtained two days before presentation (A) and on the day of admission (B) shows a migrated stent in the left iliac region (white arrow in $A$ ), which then shows further migration into the right iliac fossa (black arrow in $B$ ), with dilated small bowel loops in the lower abdomen and pelvis (B)

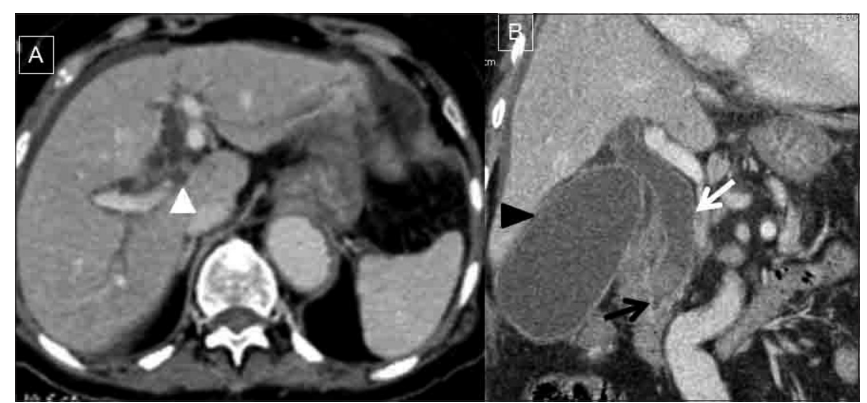

Figure $3(A, B)$ : Axial $(A)$ and coronal reformatted (B) contrastenhanced CT scans of the abdomen show an impacted sludge ball (black arrow in $\mathrm{B}$ ) at the terminal common bile duct (CBD) leading to the proximal $C B D$ and intrahepatic biliary duct dilatation (white arrowhead in A). Mild pericholecystic fluid and gall bladder wall thickening (black arrowhead in B) suggest acute cholecystitis

the dislodged / migrated biliary stent. In view of sepsis and deranged liver function tests, urgent percutaneous biliary drainage (PTBD) was attempted, which failed as the patient was uncooperative; hence, a cholecystostomy was performed. After her biliary sepsis settled, the patient underwent a successful nonoperative endoscopic removal of the migrated stent. The postoperative period was uneventful.

\section{Discussion}

First introduced in 1979, endoscopy-guided plastic biliary stent insertion has a well-established role in a wide variety of obstructive biliary and pancreatic disorders. ${ }^{[2-4]}$

The most common complications are stent occlusion and cholangitis. ${ }^{[5,6]}$ Other less common complications include cholecystitis, duodenal perforation, bleeding, pancreatitis, and stent fracture. ${ }^{[3,4,7-10]}$ Bowel wall penetration resulting in enteroenteric fistula formation, sigmoid diverticular

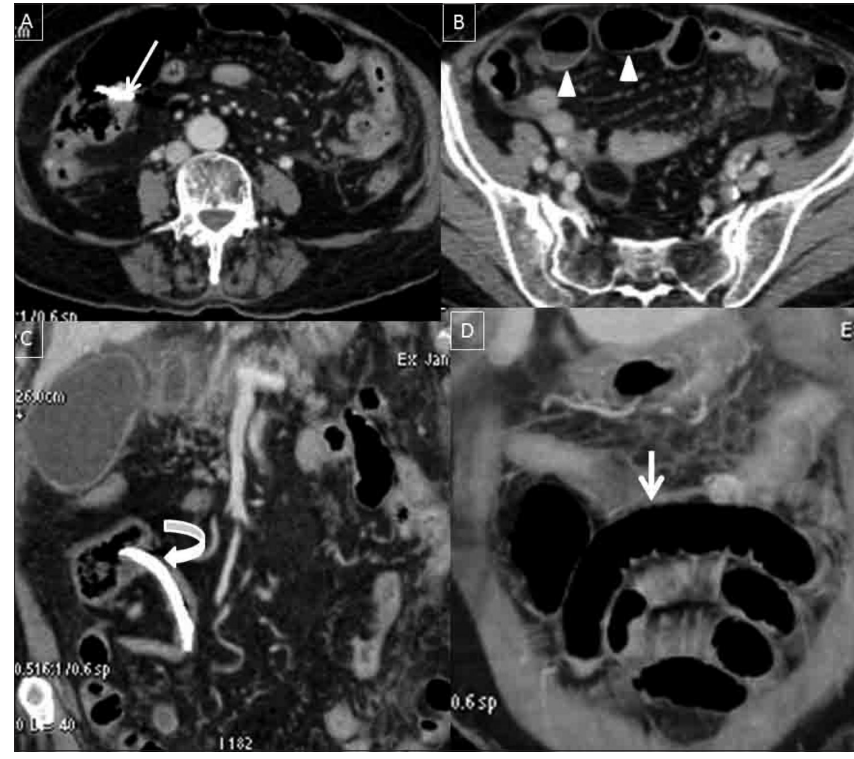

Figure 2 (A-D): Axial $(A, B)$ and coronal reformatted $(C, D)$ contrastenhanced CT scans of the abdomen and pelvis show the migrated stent entrapped at the ileocecal junction (white arrow in A), protruding into the cecal lumen (curved arrow in c), with resultant dilatation of the small bowel loops with mild fluid accumulation (white arrow heads in $\mathrm{B}$, arrows in $\mathrm{D}$ ). The distal small bowel loops are edematous with inflammatory fat stranding in the adjacent mesentery

perforation, ${ }^{[6]}$ and perforations of the small bowe ${ }^{[11]}$ have been reported. Distal stent migration occurs in $5-10 \%$ of the cases. ${ }^{[12]}$ Straight plastic stents, previous intra-abdominal surgery, hernia, and diverticular disease are risk factors for complications after distal stent migration. ${ }^{[13]}$ The risk of stent migration is higher in benign biliary strictures than in malignant strictures. Multiple biliary stent placements decrease the frequency of migration. Increasing indications for stent insertion have contributed to a growing number of reports relating to unusual distal intestinal complications. ${ }^{[13]}$

In this case, imaging showed a migrating stent, for over two days, leading to gradual intestinal obstruction, and also helped in the simultaneous diagnosis of biliary obstruction complicated by acute cholecystitis. Both complications were related to the migrated biliary stent and were tackled nonoperatively in a stepwise manner.

\section{References}

1. Johanson JF, Schmalz MJ, Geenen JE. Incidence and risk factors for biliary and pancreatic stent migration. Gastrointest Endosc 1992;38:341-6.

2. Seitz U, Valdeyar H, Soehendra N. Prolonged patency with a new-design teflon biliary prosthesis. Endoscopy 1994;26:478-82.

3. Deviere J, Baize M, de Toeuf J, Cremer M. Long-term follow up of patients with hilar malignant stricture treated by endoscopic internal biliary drainage. Gastrointest Endosc 1988;34:95-101.

4. Deviere J, Devaere S, Baize M, Cremer M. Endoscopic biliary drainage in chronic pancreatitis. Gastrointest Endosc 1990;36: 96-100. 
5. Blake AM, Monga N, Dunn EM. Biliary stent causing colovaginal fistula: Case report. JSLS 2004;8:73-5.

6. Lenzo NP, Garas G. Biliary stent migration with colonic diverticular perforation. Gastrointest Endosc 1998;47:543-4.

7. Lowe GM, Bernfield JB, Smith CS, Matalon TA. Gastric pneumatosis: Sign of biliary stent-related perforation. Radiology 1990;174:1037-8.

8. Mueller PR, Ferrucci JT Jr, Teplick SK, van Sonnenberg E, Haskin $\mathrm{PH}$, Butch RJ, et al. Biliary stent endoprosthesis: Analysis of complications in 113 patients. Radiology 1985;156:637-9.

9. Lahoti S, Catalano MF, Geenen JE, Schmalz MJ. Endoscopic retrieval of proximally migrated biliary and pancreatic stents: Experience of a large referral center. Gastrointest Endosc 1998;47:486-91.
10. Baty V, Denis B, Bigard MA, Gaucher P. Sigmoid diverticular perforation relating to the migration of a polyethylene endoprosthesis. Endoscopy 1996;28:781

11. Mistry BM, Memon MA, Silverman R, Burton FR, Varma CR, Solomon $\mathrm{H}$, et al. Small bowel perforation from a migrated biliary stent. Surg Endosc 2001;15:1043.

12. Diller R, Senninger N, Kautz G, Tübergen D. Stent migration necessitating surgical intervention. Surg Endosc 2003;17:1803-7.

13. Barton RJ. Migrated double pigtail biliary stent causes small bowel obstruction. J Gastroenterol Hepatol 2006;21:783-4.

Source of Support: Nil, Conflict of Interest: None declared.

\section{Staying in touch with the journal}

1) Table of Contents (TOC) email alert

Receive an email alert containing the TOC when a new complete issue of the journal is made available online. To register for TOC alerts go to www.ijri.org/signup.asp.

\section{2) RSS feeds}

Really Simple Syndication (RSS) helps you to get alerts on new publication right on your desktop without going to the journal's website. You need a software (e.g. RSSReader, Feed Demon, FeedReader, My Yahoo!, NewsGator and NewzCrawler) to get advantage of this tool. RSS feeds can also be read through FireFox or Microsoft Outlook 2007. Once any of these small (and mostly free) software is installed, add www.ijri.org/rssfeed.asp as one of the feeds. 